\title{
Study of reproductive health problems in adolescent girls at ESIC PGIMSR, MGM Hospital, Parel, Mumbai: a retrospective study
}

\author{
Jaya K. Gedam*
}

Department of Obstetrics and Gynecology, ESI PGIMSR, Model Hospital, Andheri (E), Mumbai, Maharashtra, India

Received: 15 August 2017

Accepted: 19 August 2017

\section{*Correspondence:}

Dr. Jaya K. Gedam,

E-mail: jayagedam@gmail.com

Copyright: (C) the author(s), publisher and licensee Medip Academy. This is an open-access article distributed under the terms of the Creative Commons Attribution Non-Commercial License, which permits unrestricted non-commercial use, distribution, and reproduction in any medium, provided the original work is properly cited.

\begin{abstract}
Background: There are almost 200 million adolescents in India. It is estimated that the adolescent group constitutes about one fifth of India's population and it is estimated that this age group will grow to over 214 million by 2020 . The period of adolescence for a girl is a period of physical and psychological preparation for safe motherhood. Several factors contribute to the adolescents' growth. A vast majority of adolescent girls in India are suffering from menstrual problems, reproductive morbidities and nutritional deficiencies such as dysmenorrhoea, pre-menstrual syndrome, irregular menses, heavy menstrual bleeding, amenorrhoea, white discharge per vagina, UTI, anaemia etc. So, the present study was carried out to assess menstrual problems, reproductive health problems and nutritional status of adolescent girls coming to our hospital.

Methods: It is a Retrospective study to find about the menstrual problems, reproductive health problems and nutritional status among the adolescent girls of 10-19 years age group who attended O.P.D. for various health problems. Data was collected retrospectively for two years from December 2015.

Results: Mean age of adolescent girls were 14.38 Mean age to attain menarche was 12.93. About 386 (96.34\%) adolescent girls were literate. $62.04 \%$ and $29.58 \%$ of adolescent girls belonged to class IV and Class V respectively. $62.56 \%$ of them live in poor housing and environmental status. The source of health information for the majority 123 $(32.2 \%)$ was from mass media. Frequency and percentages of common menstrual problems like dysmenorrhea, premenstrual syndrome, heavy menstrual bleeding, intermenstrual bleeding and primary amenorrhoea were $29.58 \%$, $26.39 \%, 16.49 \%, 24.34$ and $1.57 \%$ respectively. Other Reproductive health problems white discharge per vagina, itching in private parts, pain in lower abdomen, backache, urinary tract infection, lump in abdomen and others (boils, ulcers, warts etc.) $26.7 \%, 8.11 \%, 18.06 \%, 12.3 \%, 7.32 \%, 4.97 \%$ and $1.57 \%$. Under weight were $21.98 \%$. Anemia was observed in $57.84 \%$ of adolescent girls.

Conclusions: Present study concluded that most of the adolescent girls suffer from various types of menstrual problems, reproductive morbidities and nutritional problems. The findings of the present study recommend that awareness should be created among the adolescent girls, so that they will be able to take appropriate decision on medical care and treatment.
\end{abstract}

Keywords: Adolescent girls, Menstrual Problems, Nutritional status, Reproductive health morbidities

\section{INTRODUCTION}

World Health Organization has defined adolescence as a period between 10-19 years of age. ${ }^{1}$ Adolescence is defined as period of personal development during which young people develops a personal sense of individual identity and feeling of self-worth, which also includes an alteration of his or her body image, adaptation to more mature intellectual abilities, adjustment to society's demand for behavioural maturity, internalizing personal 
value system and preparing for adult role. $^{2}$ It is a changing stage of physical, physiological and psychological development from puberty to adulthood. At present, more than 1.2 billion are adolescents in the world this means that roughly one in every six persons is an adolescent. $^{3}$ About $21 \%$ of Indian population is adolescents (about 243 million). ${ }^{4}$ India has the largest adolescent population in the world.

They are the future of the nation, forming a major demographic and economic force. It is a period of preparation for undertaking greater responsibilities like familial, social, cultural and economic issues in adulthood. It is particularly a special period in girl's life that requires specific and special attention. This period is marked with onset of menarche. In India majority of adolescent girls are suffering from menstrual problems and other reproductive health problems such as dysmenorrhea, premenstrual syndrome, heavy menstrual bleeding, intermenstrual bleeding, white discharge per vagina, UTI anemia etc. Adolescent girls are the worst sufferers of the ravages of various forms of malnutrition viz. protein energy malnutrition, iron, iodine, calcium, vitamin A and other specific nutrient deficiencies because of their increased nutritional needs and low social power. ${ }^{5}$ The present study was planned to find out the health profile of urban adolescent girls and the associated social correlates and other contributory factors.

The study was undertaken to assess menstrual problems, reproductive health problems and nutritional status of adolescent girls.

\section{METHODS}

It is a Retrospective study to find about the menstrual problems, reproductive health problems and nutritional status of adolescent girls of 10-19 years age group who attended O.P.D. at ESI-PGIMSR, MGM Hospital, Parel, for various health problems. Data was collected retrospectively for 2 years from December 2015. A detailed history was taken and information was collected about socio-demographic characteristics and other contributory factors responsible for menstrual problems, reproductive morbidities and nutritional status followed by physical examination. Required investigations to confirm the morbidities were done. Haemoglobin estimation was done by Sahli's Haemoglobinometer.

\section{Terms used in study}

- Adolescent Girl: Girls between the ages of 10-19 years.

- Regular menstrual cycle: Cycle that occurs every 28 $\pm 2-3$ days in which the menstrual flow lasts for 35 days with an average flow of 50- $200 \mathrm{ml}$.

- Irregular menstrual cycle: Any deviation from cyclic occurrence of menstrual cycle i.e. 28 2 2-3 days.

- Dysmenorrhoea: Refers to the lower abdominal pain accompanying the menstrual cycle. Premenstrual syndrome: symptoms like abdominal pain, leg cramps, headache, low backache, breast tenderness, irritability etc. before onset of menstruation.

- Amenorrhea (primary): Total absence of menstruation in girls upto the age of completed 16 years.

- Heavy Menstrual Bleeding: Excessive menstrual blood loss which interferes with the woman's physical, emotional, social, and material quality of life, and which can occur alone or in combination with other symptoms.

- Irregular menstrual bleeding: A range of varying lengths of bleeding-free intervals exceeding 20 days within one 90-day reference period

- Haemoglobin Estimation: Haemoglobin estimation was done by Sahli's method using haemoglobinometer. Cut off level of $\mathrm{Hb}(\mathrm{g} / \mathrm{dl})$ for anaemia in adolescent girls was taken as follows Non-pregnant: $\mathrm{Hb}<12 \mathrm{~g} / \mathrm{dl}$, Pregnant: $\mathrm{Hb}<11 \mathrm{~g} / \mathrm{dl} .^{6}$

- Grades of anaemia: Anaemia was graded as mild, moderate and severe. ${ }^{7}$

- Social Class: Modified Kuppuswamy classificationwas used. ${ }^{8,9}$

- Dietary Habits: Dietary habits were classified arbitrarily into vegetarian a person who never ate animal products other than dairy milk products. Nonvegetarian a person who ate animal products other than dairy milk products at least once in a while.

The housing and environmental sanitation criteria was taken as given by Garg et al. ${ }^{10}$

\section{Inclusion criteria}

All adolescent girls (10 to 19 years) with or without attainment of menarche were included in the study.

\section{Exclusion criteria}

Girls below 10 years and above 19 years.

\section{Statistical analysis}

The data so collected were compiled in MS Excel and analyzed into tabular and graphical form. Chi-square test was used to assess the statistical association between socio-economic characteristics, reproductive morbidities, common menstrual problems and nutritional status.

\section{RESULTS}

The demographic characteristics of adolescent girls showed, out of the 382 adolescent girls, majority, 219 $(57.3 \%)$ of them belonged to the age group of 15-19 years. Mean age was $14.38 \pm 2.36$, standard error of the mean $\left(\mathrm{SE}_{\overline{\mathrm{x}}}\right): 1.6,95 \%$ confidence interval (11.63-17.12). Most, $313(81.93 \%)$ girls attained menarche at the age of 13-16 years. Mean age to attain menarche was 12.93 \pm 0.76 , Standard Error of the Mean $\left(\mathrm{SE}_{\overline{\mathrm{x}}}\right)$ : 0.039, 
95\% confidence interval (12.83-13.08). About 386 (96.34\%) adolescent girls were literate, 21 (5.49\%) girls were graduate. About $109(28.53 \%)$ mothers and 137 $(35.865 \%)$ fathers had middle school level of education. Graduate fathers and mothers were 16 (4.18\%) and 7 $(1.83 \%)$. The chi-square static is 89.0409 . The p-value is
$<0.00001$. The result is significant at $\mathrm{p}<0.05$. Maximum number of adolescents, $258(67.5 \%)$ belonged to Hindu religion, $62.04 \%$ and $29.58 \%$ of adolescent girls belonged to class IV and Class $\mathrm{V}$ respectively. The chi-square static is 9.4366 . The p-value is 0.00839 .

Table 1: Socio-demographic characteristics of the adolescent girls $(\mathrm{N}=382)$.

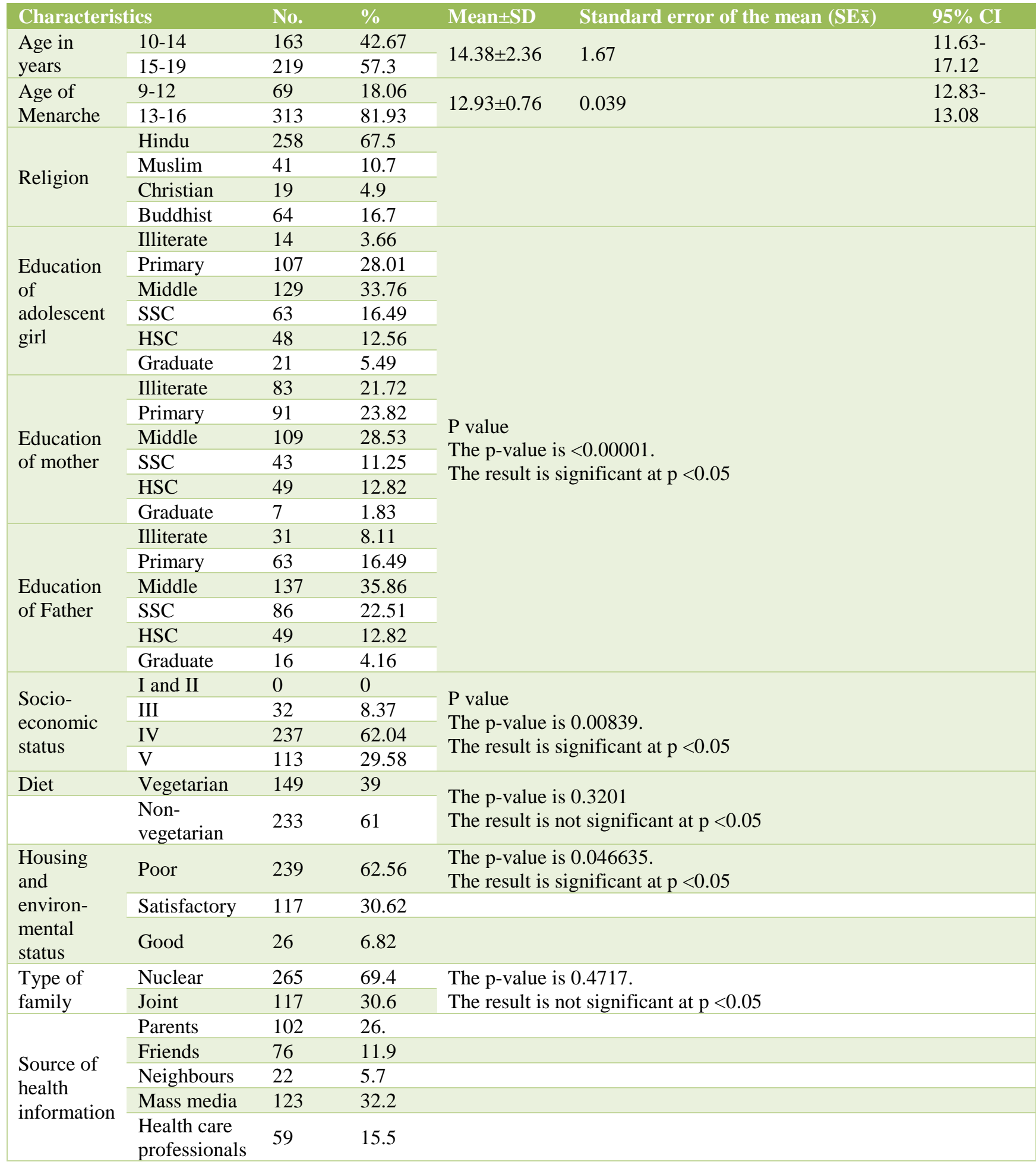


The result is significant at $\mathrm{p}<0.05$. Adolescent girls who were non-vegetarian were $61 \%$. 265 (69.4\%) of adolescent girls belonged to nuclear family and $62.56 \%$ of them live in poor housing and environmental status. The chi-square static is 6.1308 . The $\mathrm{p}$-value is 0.046635 . The result is significant at $\mathrm{p}<0.05$. The source of health information for the majority $123(32.2 \%)$ was from mass media (Table 1).

Out of 382 adolescent girls $216(57.5 \%)$ had regular and $166(42.5 \%)$ had irregular menstrual cycle (Figure 1).

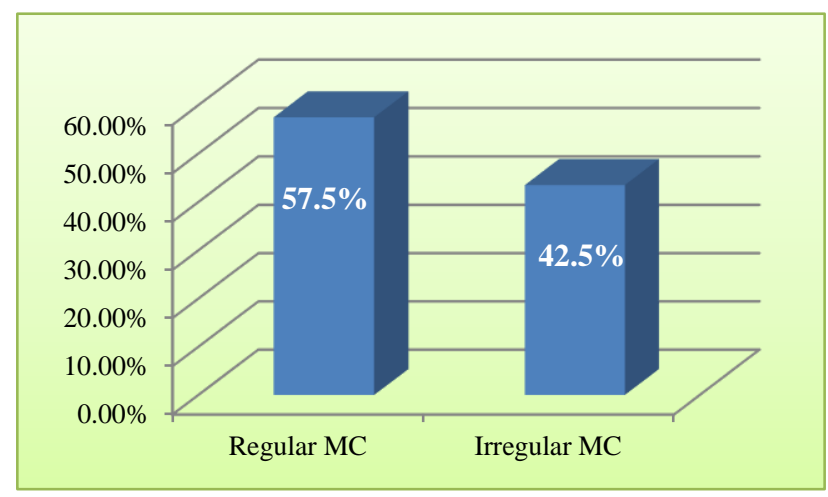

Figure 1: Menstrual cycle pattern.

Out of 382 adolescent girls, frequency and percentages of common menstrual problems like dysmenorrhea, premenstrual syndrome, heavy menstrual bleeding, intermenstrual bleeding, were 113 (29.58\%), 101 (26.39\%), 63 (16.49\%) and 93 (24.34\%) respectively.
Girls who had not yet attained menarche (primary amenorrhoea) were $6(1.57 \%)$ (Table 2$)$.

Table 2: Menstrual problems in adolescent girls.

\begin{tabular}{|lll|}
\hline Menstrual Problems & No. & $\%$ \\
\hline Dysmenorrhoea & 113 & 29.58 \\
\hline Premenstrual syndrome & 101 & 26.39 \\
\hline Heavy menstrual bleeding & 63 & 16.49 \\
\hline Irregular menstrual bleeding & 93 & 24.34 \\
\hline Amenorrhoea & 6 & 1.57 \\
\hline
\end{tabular}

Table 3: Reproductive health problems in adolescent girls.

\begin{tabular}{|lll|}
\hline Reproductive health problems & No. & $\%$ \\
\hline White discharge per vaginum & 102 & 26.7 \\
\hline Itching in private parts & 31 & 8.11 \\
\hline Pain in lower abdomen & 69 & 18.06 \\
\hline Backache & 47 & 12.3 \\
\hline UTI & 28 & 7.32 \\
\hline Lump in abdomen & 6 & 1.57 \\
\hline Others (boils, ulcers, warts) & 19 & 4.97 \\
\hline
\end{tabular}

Other Reproductive health problems identified among 382 adolescent girls were white discharge per vagina, itching in private parts, pain in lower abdomen, backache, urinary tract infection, lump in abdomen and others (boils, ulcers, warts etc) 102 (26.7\%), $31(8.11 \%), 69$ (18.06\%), $47(12.3 \%), 28(7.32 \%), 6(1.57 \%)$ and 19 $(4.97 \%)$ respectively (Table 3$)$.

Table 4: Nutritional Status (BMI) and Anaemia in adolescent girls (N=382).

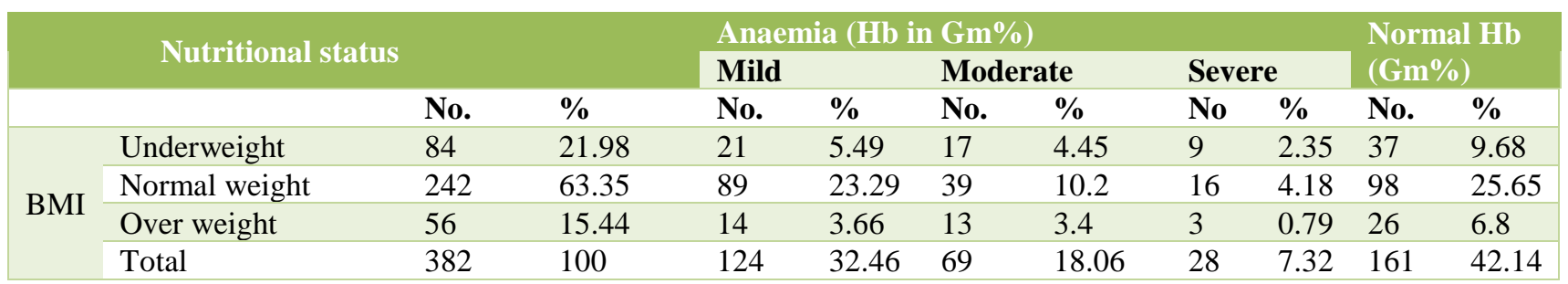

Chi-square score is $7.85, \mathrm{P}-$ value is 0.005 . The result is significant at $\mathrm{P}<0.05$

Table 5: Association between menstrual problems with nutritional status (BMI) and anaemia in adolescent girls $(\mathrm{N}=382)$.

\begin{tabular}{|c|c|c|c|c|c|c|c|}
\hline \multirow{2}{*}{$\begin{array}{l}\text { Reproductive } \\
\text { morbidities }\end{array}$} & \multicolumn{3}{|c|}{ Nutritional Status (BMI) } & \multicolumn{4}{|c|}{ Anaemia } \\
\hline & Under weight & Normal weight & Over weight & Mild & Moderate & Severe & Normal \\
\hline Dysmenorrhoea & 23 & 77 & 13 & 37 & 23 & 5 & 48 \\
\hline Premenstrual syndrome & 21 & 64 & 16 & 23 & 15 & 4 & 59 \\
\hline Heavy menstrual bleeding & 11 & 41 & 11 & 29 & 19 & 11 & 4 \\
\hline Irregular menstrual bleeding & 19 & 59 & 15 & 34 & 11 & 7 & 41 \\
\hline Amenorrhoea & 4 & 1 & 1 & 1 & 1 & 1 & 3 \\
\hline
\end{tabular}


Out of 382 adolescent girls, $84(21.98 \%)$ were under weight, $56(15.44 \%)$ were over weight and anemia of mild, moderate and severe grade was observed in 124 (32.46\%), $69(18.06 \%)$ and $28(7.32 \%)$ adolescent girls respectively. About 161 (42.14\%) adolescent girls were not having anemia. Significant association was observed between nutritional status (BMI) and anemia among the adolescents girls (Table 4).

Of the adolescent girls with common menstrual problems such as dysmenorrhea, premenstrual syndrome, heavy menstrual bleeding, irregular menstrual bleeding, amenorrhoea $29.58 \%, 26.39 \%, 16.49 \%, 24.43 \%, 1.57 \%$ were undernourished respectively whereas $29.41 \%, 19 \%$, $26.69 \%, 23.52 \%$ and $2.26 \%$ were anemic. Statistical association existed between nutritional status of adolescent girls according to BMI (Table 5).

\section{DISCUSSION}

In the present study, $81.93 \%$ of the adolescent girls had attained menarche in the age range of 13-16years, similar with the of Yashoda S et al where $71 \%$ of adolescent girls had attained menarche at age group of 13-15years. ${ }^{11}$ In present study mean age of menarche was $12.93 \pm 0.76$ similar to 12.8 yrs in study by Mohite R V et al. ${ }^{12}$ Singh, et al who reported that the mean age at menarche among the girls was $13.6 \pm 0.83$ years. ${ }^{13}$ The age of menarche is determined by general health, genetic factors, socioeconomic and nutritional.

In the present study, primary amenorrhea has been seen in $1.57 \%$. In the study done by Mohite RV et al primary amenorrhea was seen in $0.01 \%$ of adolescent girls. ${ }^{12}$ These differences could be due to differences in geographical, environmental, nutritional, socio-economic factors and general health status. Present study showed that the majority of the adolescent girls had reported menstrual problems such as dysmenorrhea, premenstrual syndrome, heavy menstrual bleeding, intermenstrual bleeding, primary amenorrhoea. These findings are similar to the study findings of Mohite RV et al and Kulkarni MV et al. ${ }^{12,14}$

Present study has revealed $57.5 \%$ girls have regular menstruation cycles whereas $43.5 \%$ have irregular cycles. Similar finding is also observed from study by Mohite $\mathrm{RV}$ et al where $63.91 \%$ girls have regular menstruation cycles whereas $36.08 \%$ have irregular cycles. Dixit R R.et al found $66.9 \%$ girls with regular menstruation cycles. ${ }^{15}$ However study conducted by Kulkarni M et al had observed $11.16 \%$ girls with irregular menstrual cycles. ${ }^{16}$ Difference may be due to nutritional, general health and age difference of study subjects.

The present study has revealed $64.65 \%$ girls had dysmenorrhoea. Study by Mohite RV et al had revealed, $49.13 \%$ girls had a complaint of dysmenorrhoea. ${ }^{12} \mathrm{~A}$ similar finding was also reported by M. Kulkarni et al. ${ }^{16}$ The difference in the results might be due to either more tolerance in rural girls or better health care facilities in urban area.

This study had revealed that $55.75 \%$ girls complain of premenstrual syndrome. Study by Mohite RV et al revealed that $46.52 \%$ girls complain of premenstrual syndrome. ${ }^{10}$ in study $41.52 \%$ adolescent girls reported by Kulkarni M. ${ }^{16}$ Difference could be due to better tolerance in rural girls or neglect of their complaints.

In the present study, Heavy menstrual bleeding was found in $22.25 \%$ adolescent girls. In the study by Mohite $\mathrm{RV}$ et al, menorrhagia was found in $17.82 \%$ girls. $\mathrm{M}$. Kulkarni 16 and. Jogdand $\mathrm{K}$ had also observed similar findings as $16.07 \%$ and $15.96 \%$ girls with menorrhagia. ${ }^{17}$

Low level of blood hemoglobin concentration and nutritional status is often associated with irregularities of menstrual and reproductive problems among the women in reproductive age groups. This study had revealed prevalence of anemia and under nutrition as $57.84 \%$ and $21.98 \%$ respectively. In the study by Mohite et al had revealed prevalence of anemia and under nutrition as $60.43 \%$ and $40.86 \%$ respectively, however data from Mumbai indicates $88 \%$ and $61 \%$ girls to be anemic and under nourished. ${ }^{12,18}$ This high proportion could be mainly due to geographical distribution, poor environmental sanitation, poor diet and psychosocial factors.

Present study attempted to identify various types of menstrual problems, reproductive morbidities and nutritional status in adolescent girls coming to our hospital. These problems could be due to lack of awareness, habit of tolerance of problems, ignorance, or due to wrong advice by friends, neighbours as well as family members, low level of education and lack of adequate health care services in area. Majority of factors are preventable. There is a need of positive attitude towards the health of adolescents girls through establishment of health care approach.

\section{CONCLUSION}

Present study concluded that most of the adolescent girls suffer from various types of menstrual problems, reproductive morbidities and nutritional problems. The findings of the present study recommend that awareness should be created among the adolescent girls, so that they will be able to take appropriate decision on medical care and treatment.

\section{ACKNOWLEDGMENTS}

Authors would like to thank Dr. Priti Shanbaag for encouragement.

Funding: No funding sources

Conflict of interest: None declared 
Ethical approval: The study was approved by the Institutional Ethics Committee

\section{REFERENCES}

1. WHO. Adolescent nutrition: a review of the situation in selected South East Asian Countries. Geneva: WHO;2006.

2. Gary M, Ingersoll. Adolescents. Carson City. Prentice Hall College Div;1989

3. Progress for Children: A report card on adolescents. Socio-demographic profile of adolescents: Number 10 April 2012 UNICEF. Available at https://www.unicef.org/publications/files/Progress_f or_Children_-_No._10_EN_04232012.pdf

4. Strategy Handbook. Rashtriya Kishor Swasthya Karyakram. Adolescent Health Division Ministry of Health and Family Welfare Government of India. January 2014. Available at https://nrhm.gujarat.gov.in/images/pdf/RKSK_Strate gy_Handbook.pdf

5. Ganguli SK. Adolescent Health. Indian Journal of Public Health. 2003;47:21-28,6-15.

6. Vir SC. IDA Control- A Public Health Programme priority. UNICEF. Proc Nutr Soc India 1998;47:4573.

7. DeMeyer EM. Preventing and controlling Iron deficiency anaemia through primary health care, WHO, GENEVA, 1989;8-26.

8. Mishra D, Singh HP. Kuppuswamy's socioeconomic status scale $-\mathrm{a}$ revision. Indian $\mathrm{J}$ Pediatr. 2003;70(3):273-4.

9. Mahajan BK, Gupta MC. Textbook of Preventive and Social Medicine, $2^{\text {nd }}$ Ed. 1995;134-5.

10. Garg. Morbidity profile with reference to housing and environmental status criteria. Indian $\mathbf{J} \mathrm{Pub}$ Health. 1983;18:85.
11. Pavithran S, Yashoda S, Priyadharshini S, Nayak BS. Reproductive health problems and health seeking behaviour among adolescent girls of Udupi district, Karnataka. Manipal J Nursing Health Sci. 2015;1(2):87-90.

12. Mohite RV, Mohite VR, Kumbhar SM, Ganganahalli P. Common menstrual problems among slum adolescent girls of western Maharashtra, India, J Krishna Inst Med Sci Univ. 2013;2(1):89-97.

13. Singh MM, Devi R, Gupta SS. Awareness and health seeking behaviour of rural adolescent school girls on menstrual and reproductive health problems. Indian $\mathrm{J}$ Med Sci. 1999;53(10):439-43.

14. Kulkarni MV, Durge PM, Kasturwar NB. Prevalence of anemia among adolescent girls in an urban slum. Natl J Community Med. 2012;3(1):108-111.

15. Dixit RR, Sabane HH, Durge PM. Reproductive Health of Adolescent Girls in an urban population of Meerut, Uttar Pradesh. Health Population: Perspect Issues. 2009;32(4):204-9.

16. Kulkarni M, Durge PM. Reproductive Health morbidities among adolescent girls: Breaking the silence. Ethno Med 2011;5(3):165-8.

17. Jogdand K, Yerpude P. A community based study on menstrual hygiene among adolescent girls. Indian $\mathbf{J}$ Maternal Child Health. 2011;13(3):1-6.

18. Family Planning Association of India. Health camp for adolescent girls in urban slum of Mumbai. Mumbai branch FPAI, 2010.

Cite this article as: Gedam JK. Study of reproductive health problems in adolescent girls at ESIC PGIMSR, MGM Hospital, Parel, Mumbai: a retrospective study. Int J Reprod Contracept Obstet Gynecol 2017;6:4285-90. 